\title{
Doppler patterns in growth restricted foetuses: determinants and outcome in a tertiary hospital in South Kerala, India
}

\author{
Heera T. Shenoy ${ }^{1 *}$, Sheela Shenoy ${ }^{2}$, Sonia X. James ${ }^{3}$
}

\begin{abstract}
${ }^{1}$ Department of Obstetrics and Gynecology, Travancore Medical College, Kollam, Kerala, India ${ }^{2}$ Department of Obstetrics and Gynecology, Govt Medical College, Trivandrum, Kerala, India ${ }^{3}$ Department of Radiodiagnosis, Travancore Medical College, Kollam, Kerala, India
\end{abstract}

Received: 12 December 2018

Accepted: 07 January 2019

\author{
*Correspondence: \\ Dr. Heera T. Shenoy, \\ E-mail: heerarprabhu@gmail.com
}

Copyright: (c) the author(s), publisher and licensee Medip Academy. This is an open-access article distributed under the terms of the Creative Commons Attribution Non-Commercial License, which permits unrestricted non-commercial use, distribution, and reproduction in any medium, provided the original work is properly cited.

\section{ABSTRACT}

Background: Foetal growth restriction refers to a condition in which the foetus is unable to achieve its genetically determined growth potential. Doppler velocimetry in FGR not only decides the optimum time of delivery but also the optimum mode of delivery and so authors evaluated the Doppler patterns in growth restricted fetuses.

Methods: Nested case-control study conducted among normal and abnormal Doppler groups at a tertiary care teaching hospital in the year 2017.

Results: Among 82 growth restricted foetuses, 54 of them had normal Doppler patterns $(65.85 \%)$ and 28 had abnormal Doppler patterns (34.15\%).13(46.5\%) had umbilical S/D elevation,2 (7.14\%) had AEDV,1(3.57\%) with REDV and $12(42.8 \%)$ with CPR $<1$. Mean maternal age was slightly higher in the abnormal Doppler group. FGR babies with abnormal velocity waveforms had shorter diagnosis to delivery interval than those with normal Doppler and decision for delivery was taken at a lower gestational age. ( $p$ value-0.001). Mothers of FGR babies with abnormal Doppler studies underwent emergency caesarean section for non-reassuring foetal heart patterns. ( $p$ value-0.001) The mean birth weight was higher $(2201.80 \mathrm{gm})$ in Doppler normal FGR and it was 1929.46grams in abnormal umbilical Doppler group and 1363.33gm in AREDV (pvalue-0.001). Growth restricted with normal Doppler had shorter NICU stays than with abnormalities ( $p$ value-0.003). Term FGR went home early than early preterm. ( $p$ value-0.001).

Conclusions: Growth restricted foetuses with normal umbilical velocimetry are at a lower risk than those with abnormal velocimetry in terms of prolonged diagnosis-delivery interval and shorter NICU days. The need for neonatal resuscitation at birth was more in babies with abnormal Doppler velocimetry and absent diastole /reversed diastolic flow of umbilical artery velocimetry.

Keywords: Abnormal, AEDV, CPR, Foetal growth restriction, Middle cerebral artery, Normal, Pattern, REDV Umbilical artery Doppler

\section{INTRODUCTION}

Foetal growth restriction refers to a condition in which the foetus is unable to achieve its genetically determined growth potential. ${ }^{1}$ It is defined as an estimated birth weight of less than $10^{\text {th }}$ percentile. Severe FGR is defined as birth weight less than third centile. Placenta-based intrauterine growth restriction (IUGR) is predominantly a vascular disorder. It starts with abnormal tertiary villous vessels and ends with characteristic foetal multi-vessel cardiovascular manifestations. ${ }^{2}$ According to an estimate, approximately 30 million new-borns per year are affected with intrauterine growth restriction in developing countries. This rate is six times higher than that in 
developed countries. The highest burden of prevalence of IUGR babies lies in Asia (75\%), mainly South East Asia, followed by Africa (20\%) and Latin America (5\%). ${ }^{3}$ FGR is associated with Doppler signs suggesting hemodynamic redistribution as a reflection of foetal adaptation to undernutrition/hypoxia, histological and biochemical signs of placental disease and a higher risk of preeclampsia. IUGR can lead to increased perinatal morbidity and mortality and impaired neurodevelopment. There is a high incidence of intrauterine foetal demise, intrapartum foetal distress and operative deliveries in FGR. Perinatal mortality rates are substantially higher for growth-restricted infants. Diverse factors including foetal condition as well as maternal and environmental factors can lead to FGR.

Ultrasonogram is frequently done in antenatal period to assess foetal size (estimated baby weight) through serial foetal biometry measurements. Biophysical profile (BPP) and amniotic fluid index (AFI). Doppler ultrasound has an important contribution to make to the surveillance of growth-restricted foetuses. As IUGR worsens, Doppler abnormalities in these vascular territories also deteriorate, suggesting a sequential pattern of disease progression accelerated by hypertension4. This presumed sequence and the anticipation of foetal deterioration form the basis for Doppler surveillance in IUGR. Deterioration in Doppler findings typically leads to several changes in clinical IUGR management: increased monitoring frequency, administration of antenatal steroids and delivery. ${ }^{5}$ The Doppler patterns follow a longitudinal trend with early changes in the umbilical artery and middle cerebral artery followed by other peripheral arteries. They indicate the redistribution of blood flow in growth-restricted foetuses and need for close monitoring of the foetus. Umbilical artery velocimetry is a good predictor in these growth restricted foetuses at risk of antenatal compromise. ${ }^{6}$ Fetal middle cerebral artery Doppler gives information on uteroplacental perfusion and foetal brain oxygenation status. Then venous changes appear in the severely compromised foetus. These are strong predictors of poor perinatal outcome and indicate impending irreversible damage. Among them umbilical artery systolic/ diastolic (S/D) ratio, resistance index (RI) and pulsatility index (PI) are used most commonly and cerebro-placental ratio. CPR is calculated by dividing the middle cerebral artery (MCA) Pulsatility Index by the UA Doppler Pulsatility Index and reflects in a combined fashion mild increases in placental resistance with mild reductions in fetal brain vascular resistance and is demonstrated to be more sensitive to hypoxia than its individual components and correlates better with adverse outcome. ${ }^{7}$ Since the CPR includes the UA, it can replace its use for the detection of FGR at any gestational age. Before 34 weeks, FGR associated with Doppler abnormality affects umbilical artery S/D ratio>3.0 followed by worsening of Doppler manifested as absent end diastolic flow velocity (AEDV) and reversal of end diastolic flow velocity (REDV). Near term, when umbilical artery changes are subtle, decreases in MCA Doppler indices and reversal of CPR is noted.

Doppler velocimetry not only decides the optimum time of delivery but also the optimum mode of delivery. Among fetuses below the $10^{\text {th }}$ centile, those with an estimated fetal weight $(\mathrm{EFW})<\mathrm{p} 3$ have a much higher risk of adverse perinatal outcome irrespective of the CPR and UtA Doppler indices. ${ }^{8}$ Therefore, when either CPR, uterine artery PI or EFW $<\mathrm{p} 3$ is abnormal, the risk of adverse perinatal outcome is increased. Surveillance of high risk pregnancies with Doppler velocimetry of umbilical and fetal arteries with appropriate timely obstetric intervention leads to a reduction of $29 \%$ in stillbirths". 9 The present study compared Doppler patterns in FGR and evaluated the determinants, maternal co-morbidities, diagnosis-delivery intervals in normal and abnormal Doppler, association of Gestational age and birth weight in abnormal Doppler and neonatal morbidities in FGR.

\section{METHODS}

The study population consisted of 82 women with singleton pregnancies who gave birth to neonates with birthweights less than the 10th centile (FGR). New-borns with birth weight below 10th percentile for gestational age on the chart of foetal growth were classified as having foetal growth restriction (FGR).

They were grouped into:

- Group 1-Normal Doppler FGR

- Group 2-Abnormal Doppler FGR.

This nested case control study was conducted in Department of Obstetrics and Gynaecology, Travancore Medical College, a tertiary care teaching hospital in South Kerala in the year 2017 (January to December).

\section{Inclusion criteria}

- $\quad$ Singleton pregnancy

- Gestational age more than 28 weeks

- Birth weight less than $10^{\text {th }}$ percentiles of the corresponding gestational age on the chart of foetal growth

- Normal fetal anatomy

- Delivered at Travancore Medical College and NICU care obtained here.

\section{Exclusion criteria}

- Gestational age<28weeks

- Fetus with diagnosed chromosomal anomalies or structural anomalies.

- Multifetal gestation,

- PPROM. 
The data on birth was obtained from the computerised database maintained in the hospital information system of Travancore Medical College. Only cases with recorded birthweights and gestational age at the time of delivery (determined by either date of LMP or dating scan) were included in the final data base. The fetal biometry included assessment of biparietal diameter (BPD), head circumference (HC), abdominal circumference (AC), and femoral length (FL). Fetal weight according to the Hadlock formula that uses FL, AC and BPD was also noted. Amniotic fluid index (AFI) was calculated by adding the vertical depths of the largest pocket in each of the four uterine quadrants. Oligohydramnios was considered when AFI was eight or less without premature rupture of membranes. Once FGR was diagnosed, the women underwent pulsed wave Doppler studies using GE $700 \mathrm{MR}$ with $3.5 \mathrm{MHz}$ curvilinear transducer of Fetal umbilical artery (UA) and middle cerebral arteries (MCA) by an expert sonologist.

The umbilical artery was identified, and flow velocity waveforms were obtained from free-floating loop of cord. The systolic/ diastolic (S/D) ratio of the umbilical artery and absence or reversal of end diastolic velocity were noted. Antenatal steroid administration was given to women as per NIH guidelines. In a structured questionnaire, maternal age, domicile, parity, comorbidities, sociodemographic details, infertility treatment, previous obstetric career, h/o FGR in previous pregnancy, gestational age at diagnosis and delivery were noted. Course in hospital and if Caesarean, whether emergency or elective and the indication for the procedure was noted. All the subjects were kept under strict surveillance till confinement and were monitored with CTG, BPP and Doppler velocimetry study.

Following criteria were considered for decision regarding delivery: Absent diastole or reversal of diastolic flow, abnormal fetal heart tracing, worsening of maternal condition e.g. imminent eclampsia, HELLP. Gestational age $>32$ weeks in the group with high resistance diastolic flow, severe fetal growth restriction with AFI <5, gestation $>37$ weeks.

The neonatal outcome was evaluated in terms of birthweight, Apgar, NICU admission, need to resuscitation, length of NICU stay and morbidities like sepsis, respiratory distress and hyperbilirubinemia and others. The antenatal Doppler evaluation results were compared with birthweights and neonatal outcome like NICU admissions, length of NICU stay, need for ventilator, AFI, BPP, NST and centiles. Neonatal morbidity. NICU stay of 5 days, 6-10 days and 10 days corresponded to mild, moderate and severe neonatal morbidity respectively.

\section{Statistical analysis}

All the data was entered into Microsoft excel software and analysed using SPSS16 for windows. Descriptive analysis was done. Chi Square /Fischer Exact has been used to find the significance of study parameters and $\mathrm{p}$ value of $<0.05$ was considered significant.

\section{FGR mothers}

\section{- Group 1: Doppler normal}

- Group 2: Doppler abnormal.

\section{Interpretation of Doppler findings}

The umbilical artery measurements were made from free loop of cord midway between the placental and abdominal wall insertion. On the one hand, increased UA Doppler PI has a great clinical value for the identification of FGR, alone or combined in the CPR ratio. On the other hand, the progression of UA Doppler patterns to absent or reverse end-diastolic flow correlates with the risks of injury or death

The middle cerebral artery was located in a transverse plane at the level of the lesser wing of the sphenoid bone with sample gate placed on proximal portion of the vessel.

\section{Abnormal Doppler is diagnosed when}

\section{Stage I Foetal Growth Restriction}

\section{Umbilical Artery}

- $\mathrm{S} / \mathrm{D}$ ratio $>3$

- $\quad$ S/D value $>95$ th percentile of reference values

\section{Middle cerebral artery}

- $\mathrm{MCA} / \mathrm{UA}$ PI ratio (CPI) or less than 2SD.

- $\mathrm{MCA} / \mathrm{UA} \mathrm{S} / \mathrm{D}$ ratio less than 1

Stage II Foetal Growth Restriction

- If the diastolic flow was absent end diastolic flow velocity (AEDV)

\section{Stage III Foetal Growth Restriction}

- $\quad$ Reversed end diastolic flow velocity (REDV).

\section{RESULTS}

\section{Sociodemographic profile and Doppler patterns}

Mean maternal age of normal Doppler group was 27.05 years while it was slightly higher, 29.25years in abnormal Doppler group.

There was no major difference in parity and domicile between mothers with FGR babies of normal Doppler and those with abnormal Doppler velocimetry studies. 
Table 1: Socio-demographic profile and Doppler patterns.

\begin{tabular}{|c|c|c|}
\hline Characteristic & $\begin{array}{l}\text { Normal } \\
\text { Doppler } \\
(n=54)\end{array}$ & $\begin{array}{l}\text { Abnormal } \\
\text { Doppler } \\
(\mathbf{n}=\mathbf{2 8})\end{array}$ \\
\hline \multicolumn{3}{|c|}{ Maternal age (years) } \\
\hline$<20$ & $1(1.8)$ & $1(3.57)$ \\
\hline $20-24$ & $13(24.07)$ & $5(17.8)$ \\
\hline $25-29$ & $27(50)$ & $9(32.14)$ \\
\hline $30-34$ & $10(18.5)$ & $10(35.17)$ \\
\hline$>35$ & $3(5.55)$ & $3(10.17)$ \\
\hline \multicolumn{3}{|l|}{ Gravida } \\
\hline G 1 & $21(38.8)$ & $13(46.4)$ \\
\hline G 2 & $26(48.8)$ & $12(42.8)$ \\
\hline G 3 & $7(12.96)$ & $3(10.8)$ \\
\hline \multicolumn{3}{|l|}{ Domicile } \\
\hline Urban & $48(88.9)$ & $19(67.8)$ \\
\hline Rural & $6(11.1)$ & $9(32.2)$ \\
\hline \multicolumn{3}{|c|}{ Status of subject } \\
\hline Booked & $42(78)$ & $18(64)$ \\
\hline Referred & $12(22)$ & $10(36)$ \\
\hline
\end{tabular}

\section{Reproductive career and Doppler patterns}

The obstetric history suggested a higher incidence of growth restriction in previous pregnancy in the mothers of the abnormal Doppler group ( $p$ value 0.0010). There were three mothers with bad obstetric history in group 2 abnormal Doppler group.

Table 2: Reproductive career and Doppler patterns.

\begin{tabular}{|c|c|c|c|}
\hline Characteristic & $\begin{array}{l}\text { Normal } \\
\text { Doppler } \\
(\mathbf{n}=\mathbf{5 4})\end{array}$ & $\begin{array}{l}\text { Abnormal } \\
\text { Doppler } \\
(\mathrm{n}=28)\end{array}$ & $\begin{array}{l}\mathbf{P} \\
\text { value }\end{array}$ \\
\hline \multicolumn{4}{|l|}{$\begin{array}{l}\text { Infertility } \\
\text { treated }\end{array}$} \\
\hline Yes & $16(29)$ & $08(29)$ & 0.920 \\
\hline No & $38(71)$ & $20(71)$ & \\
\hline \multicolumn{4}{|l|}{$\mathrm{H} / \mathrm{O}$ abortion } \\
\hline Yes & $20(37)$ & $05(17.8)$ & 0.073 \\
\hline No & $34(63)$ & $23(82.8)$ & \\
\hline \multicolumn{4}{|l|}{$\begin{array}{l}\text { Previous } \\
\text { obstetric H/O }\end{array}$} \\
\hline FTND & $11(20)$ & $08(28.5)$ & 0.353 \\
\hline $\begin{array}{l}\text { Previous } \\
\text { cesarean }\end{array}$ & $22(41)$ & $07(25)$ & \\
\hline Not applicable & $21(39)$ & $13(46.5)$ & \\
\hline \multicolumn{4}{|l|}{ Previous FGR } \\
\hline Yes & $02(3.7)$ & $06(21)$ & $0.010 *$ \\
\hline No & $52(96.3)$ & $22(78)$ & \\
\hline
\end{tabular}

\section{Maternal determinants and Doppler patterns}

There was a trend for more underlying medical comorbidities in mothers with abnormal Doppler studies. HDP constituted $32 \%$ of abnormal Doppler group while there were $20 \%$ in normal Doppler group. There were more anaemic mothers $(\mathrm{Hb}<10.7)$ who received iron sucrose infusion and three of them with Haemoglobin< $6 \mathrm{gms}$ in the abnormal Doppler group who were transfused packed RBC's to avert maternal mortality.21\% $(n=5)$ foetuses with umbilical artery S/D elevation and all three with absent/reversed diastolic flow had impending eclampsia and HELLP syndrome received Magnesium sulphate and was near-miss mortality. Gestational diabetes was present in $25 \%(n=7)$ of the mothers with abnormal Doppler FGR compared to $9 \%(n=5)$ of the mothers with normal Doppler FGR. Hypothyroidism was three times more common in abnormal Doppler FGR mothers. All the three with AREDF were hypothyroidism on medication.

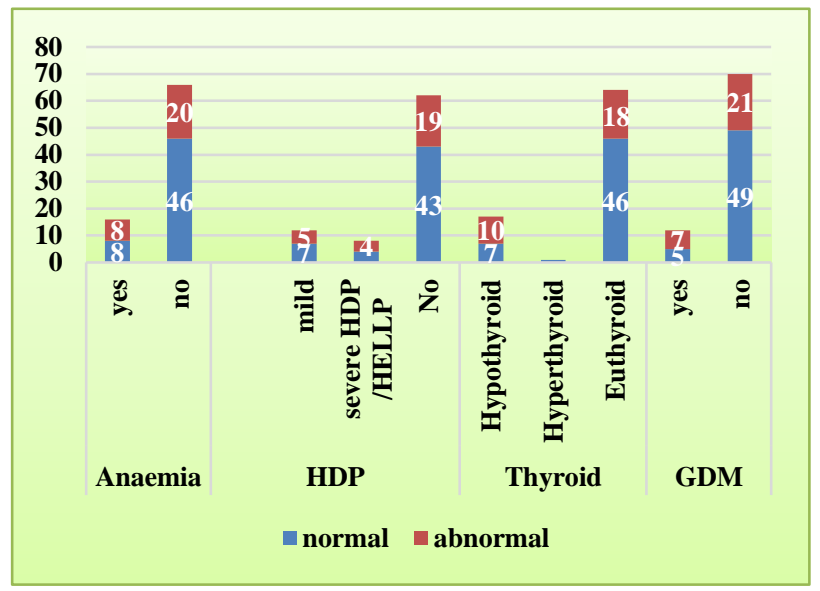

Figure 1: Maternal determinants and Doppler patterns.

\section{Diagnosis: delivery delay and Doppler patterns}

FGR babies with abnormal umbilical artery velocity waveforms had shorter diagnosis to delivery interval than those with normal Doppler and decision for delivery was taken at a lower gestational age after counselling regarding prematurity risks ( $\mathrm{p}$ value-0.001).

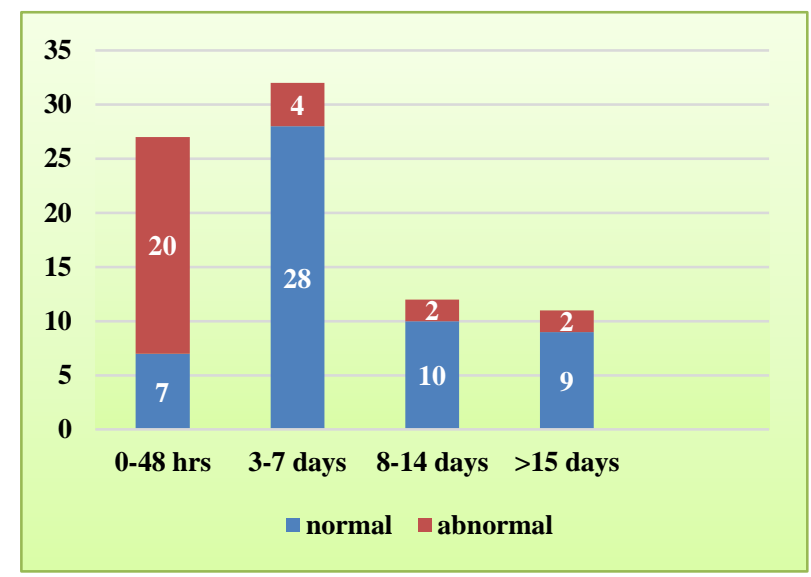

Figure 2: Diagnosis-delivery interval and Doppler patterns. 
Only 7 mothers in normal Doppler FGR had been terminated in 48 hours while in the same time frame, 20 abnormal pattern Doppler mothers underwent emergency caesarean with three AREDV mothers decided in four hours of sonological diagnosis.

The total foetuses delivered at less than 36 weeks gestation were $17(31 \%)$ in normal Doppler group, 21 (75\%) in group 2 (18 with Umbilical A S/D elevated and 2 with AEDV and 1 with REDV.) The rate of progression for Doppler abnormalities was significantly related to gestational age.

\section{Mode of outcomes and Doppler patterns}

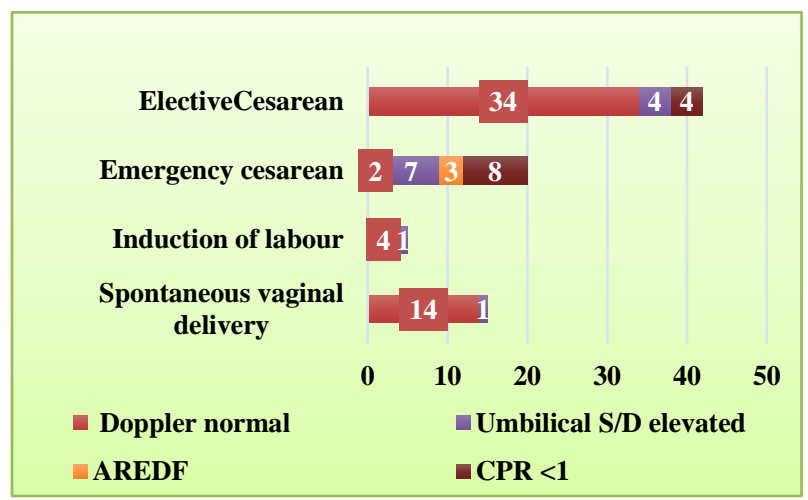

Figure 3: Labour outcome and Doppler patterns.

Mothers of FGR babies with abnormal Doppler studies underwent emergency caesarean section for nonreassuring foetal heart patterns (NRFHR) and associated oligoamnios along with medical co-morbidities. ( $\mathrm{p}$ value0.001) there was a still higher incidence of emergency caesarean section in absent diastole/reversed diastolic flow without waiting for IOL due to GA remote from term (30.4-33.5weeks).

\section{Rescue-corticosteroid prophylaxis and Doppler}

$92.8 \%$ received two doses of betnesol as per $\mathrm{NIH}$ guidelines and it was $51.8 \%$ in normal Doppler group.

Table 3: Rescue-steroid prophylaxis and Doppler.

\begin{tabular}{|l|l|l|}
\hline Steroid & $\mathbf{N}=54$ (group 1) & $\mathbf{N}=28$ (group 2) \\
\hline Yes & $28(51.8)$ & $26(92.8)$ \\
\hline No & $26(48.2)$ & $02(7.2)$ \\
\hline
\end{tabular}

\section{Gestational age at delivery, birthweight and Doppler patterns}

Doppler abnormality was statistically significant in low birth weight babies with FGR ( $p$ value-0.0009). In the present study group there is significant decrease in S/D and RI of umbilical artery as birth weight increases, the mean birth weight being higher in the normal Doppler group (gm) and lowest in the absent/ reversed end diastolic flow group.

The mean birth weight was higher $(2201.80 \mathrm{~g})$ in Doppler normal FGR and it was $1929.46 \mathrm{~g}$ in abnormal umbilical Doppler group and 1363.33g in AREDV (p value-0.001).

\section{Neonatal morbidity and Doppler patterns}

Term FGR had shorter NICU stay and preterms with abnormal doppler velocimetry had prolonged NICU stay due to neonatal morbidities necessitating intensive care $(\mathrm{p}$ value: 0.001).15 out of $22(68 \%)<37$ weeks with Doppler abnormality needed ventilator/CPAP for support while only 1 out of $26(38.46 \%)$ normal Dopplers needed CPAP.

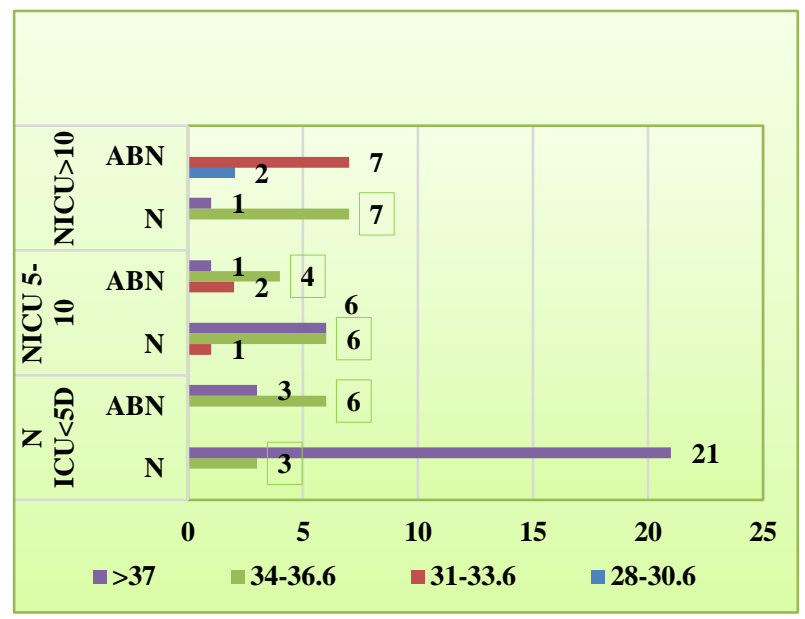

Figure 4: Gestational age and neonatal morbidity in FGR.

Sepsis, hyperbilirubinemia, Respiratory distress syndrome, prematurity, hypocalcaemia, hypoglycaemia, hypothermia were the common neonatal morbidities.

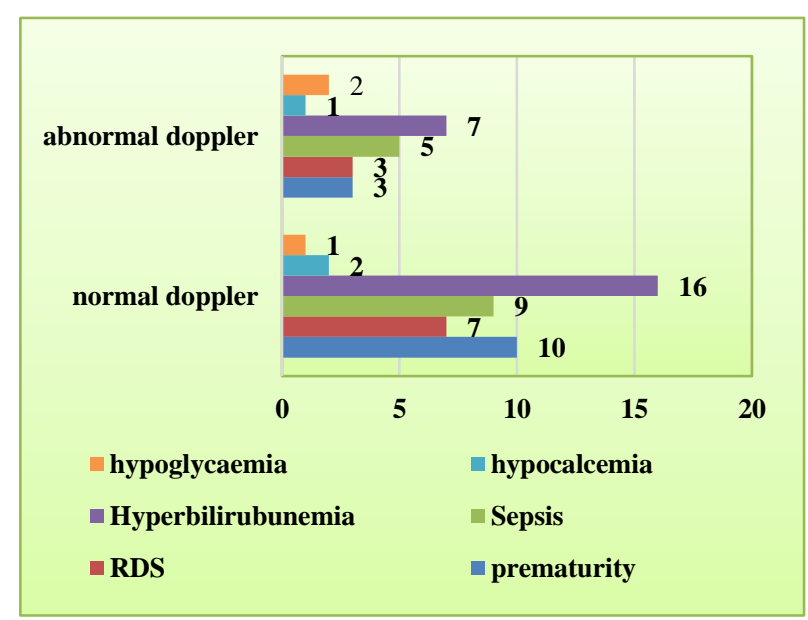

Figure 5: Distribution of neonatal morbidities (Doppler normal and abnormal). 
Table 4: Gestational age, birth weights and Doppler patterns.

\begin{tabular}{|c|c|c|c|c|c|c|c|c|c|}
\hline $\begin{array}{l}\text { Gestational } \\
\text { age in weeks }\end{array}$ & \multicolumn{2}{|c|}{$1-1.499 \mathrm{~kg}$} & \multicolumn{2}{|c|}{$1.5-1.99 \mathrm{~kg}$} & \multicolumn{2}{|c|}{$2-2.499 \mathrm{~kg}$} & \multicolumn{2}{|c|}{$>2.5 \mathrm{~kg}$} & \multirow[t]{2}{*}{ P-value } \\
\hline & $\mathbf{N}$ & $\mathbf{A B N}$ & $\mathbf{N}$ & $\mathbf{A B N}$ & $\mathbf{N}$ & $\mathbf{A B N}$ & $\mathbf{N}$ & $\mathbf{A B N}$ & \\
\hline $28-30.6$ & $3(5.55)$ & $2(7.14)$ & 0 & 0 & 0 & 0 & 0 & 0 & \multirow{5}{*}{$0.0009 *$} \\
\hline $31-33.6$ & 0 & 0 & $01(1.85)$ & $07(25)$ & $04(7.4)$ & $02(7.14)$ & 0 & 0 & \\
\hline $34-36.6$ & 0 & 0 & $04(7.4)$ & $01(3.5)$ & $19(35)$ & $12(42.8)$ & 0 & 0 & \\
\hline \multirow[t]{2}{*}{$>37$} & 0 & 0 & $04(7.4)$ & $02(7.14)$ & $16(29.6)$ & 0 & 3 & $2(7.14)$ & \\
\hline & & 05 & & 19 & & 53 & & 05 & \\
\hline
\end{tabular}

*-Statistically significant

\section{Doppler patterns and its distribution}

Among 82 growth restricted foetuses, 54 of them had normal Doppler patterns $(65.85 \%)$ and 28 had abnormal Doppler patterns (34.15\%). 13(46.5\%) had umbilical S/D elevation, 12 (42.8\%) had CPR<1,2 (7.14\%) had AEDV and there was a single case of $(3.57 \%)$ with REDV.

Table 5: Doppler patterns in FGR.

\begin{tabular}{|l|l|l|}
\hline Doppler patterns & \multicolumn{2}{|l|}{ Stage of FGR } \\
\hline Umbilical artery S/D >3 & Stage 1 FGR & $13(46.5)$ \\
\hline $\begin{array}{l}\text { Middle cerebral A/ } \\
\text { Umbilical A S/D ratio }\end{array}$ & $\begin{array}{l}\text { Stage 1 FGR } \\
\text { Sta }\end{array}$ & $12(42.8)$ \\
\hline $\begin{array}{l}\text { Absent reversed end } \\
\text { diastolic flow (AEDV) }\end{array}$ & Stage 2 FGR & $02(7.14)$ \\
\hline $\begin{array}{l}\text { Reverse end diastolic } \\
\text { flow (REDV) }\end{array}$ & Stage 3 FGR & $01(3.57)$ \\
\hline Total & & $28(100)$ \\
\hline
\end{tabular}

\section{Doppler patterns and other parameters}

Those with Amniotic fluid index $<8 \mathrm{Cm}$ had 3.7-fold risk of Doppler abnormality in FGR (p value-0.016). Oligohydramnios was associated with pregnancy induced hypertension and was about three times more commonly seen with abnormal Doppler studies Longitudinal studies in early-onset FGR foetuses have shown that the AFI fluid index progressively decreases. Nonreactive NST increased the Odds by 3.5 of Doppler abnormality necessitating imminent delivery. ( $\mathrm{p}$ value-0.010). FGR less than third centile multiplied the risk of abnormal Doppler patterns by 6.7 times when compared to birthweight less than $10^{\text {th }}$ centile (pvalue-0.001). Biophysical profile score $<8$ carried 14.2 times risk of Doppler abnormality in growth restricted foetuses. ( $p$ value-0.001).

Table 6: AFI, BPP, NST and centile and Doppler patterns.

\begin{tabular}{|c|c|c|c|c|c|c|c|}
\hline \multirow{3}{*}{ Variable } & \multirow{2}{*}{\multicolumn{2}{|c|}{ Doppler }} & \multirow{2}{*}{$\begin{array}{l}\text { Odds } \\
\text { ratio }\end{array}$} & \multicolumn{2}{|c|}{$\begin{array}{l}95 \% \text { Confidence } \\
\text { Interval }\end{array}$} & \multirow{2}{*}{$\begin{array}{l}\text { Chi } \\
\text { square }\end{array}$} & \multirow[t]{2}{*}{ p value } \\
\hline & & & & Lower & Upper & & \\
\hline & Normal & Abnormal & \multirow{3}{*}{3.7} & \multirow{3}{*}{1.232} & \multirow{3}{*}{11.298} & \multirow{3}{*}{5.808} & \multirow{3}{*}{$0.016^{*}$} \\
\hline $\mathrm{AFI}>8 \mathrm{~cm}$ & $47(87.0 \%)$ & $18(64.3 \%)$ & & & & & \\
\hline AFI $<8 \mathrm{~cm}$ & $07(13.0 \%)$ & $10(35.7 \%)$ & & & & & \\
\hline \multicolumn{3}{|l|}{ NST } & \multirow{3}{*}{3.5} & \multirow{3}{*}{1.314} & \multirow{3}{*}{9.325} & \multirow{3}{*}{6.571} & \multirow{3}{*}{$0.010^{*}$} \\
\hline Reactive & $42(77.8 \%)$ & $14(50.0 \%)$ & & & & & \\
\hline Non-reactive & $12(22.2 \%)$ & $14(50.0 \%)$ & & & & & \\
\hline \multicolumn{3}{|l|}{ BPP } & \multirow{3}{*}{14.2} & \multirow{3}{*}{4.614} & \multirow{3}{*}{43.542} & \multirow{3}{*}{25.660} & \multirow{3}{*}{$0.001 *$} \\
\hline$<8$ & $07(13.0 \%)$ & $19(67.9 \%)$ & & & & & \\
\hline$>8$ & $47(87.0 \%)$ & $09(32.1 \%)$ & & & & & \\
\hline \multicolumn{3}{|l|}{ Centile } & \multirow{3}{*}{6.7} & \multirow{3}{*}{2.267} & \multirow{3}{*}{19.889} & \multirow{3}{*}{13.277} & \multirow{3}{*}{$0.001 *$} \\
\hline$<$ Third centile & $07(13.0 \%)$ & $14(50.0 \%)$ & & & & & \\
\hline$<$ Tenth centile & $47(87.0 \%)$ & $14(50.0 \%)$ & & & & & \\
\hline
\end{tabular}

*-Significant

\section{Comparison of significant variables with Doppler}

The Gestational age at diagnosis (mean) in weeks was compared in Doppler normal and Doppler abnormal and
FGR was diagnosed earlier by nearly a week with significant $p$ value. $P$ value was not significant in the gestational age at delivery in weeks of the two groups. The mean birthweight in Doppler abnormal was 272.34 
grams lesser than in Doppler normal group ( $\mathrm{p}$ value 0.001). Perinatal morbidity in terms of NICU days (mean) was highly significant implying that growth restricted foetuses with Doppler pattern abnormality stayed mean of 3days more than the Doppler normal group (p value- 0.003 ).

Table 7: Severity of FGR, AFI and Doppler patterns.

\begin{tabular}{|c|c|c|c|c|c|c|}
\hline & \multicolumn{4}{|c|}{ Amniotic fluid index } & Chi square & p value \\
\hline Doppler & $<5 \mathrm{~cm}$ & $5-8 \mathrm{~cm}$ & $8-10 \mathrm{~cm}$ & $>10 \mathrm{~cm}$ & \multirow{3}{*}{10.004} & \multirow{3}{*}{$0.019 *$} \\
\hline Normal & $0(0.0 \%)$ & $7(53.8 \%)$ & $15(68.2 \%)$ & $32(74.4 \%)$ & & \\
\hline Abnormal & $4(100.0 \%)$ & $6(46.2 \%)$ & $7(31.8 \%)$ & $11(25.6 \%)$ & & \\
\hline Percentile & & & & & \multirow{3}{*}{14.491} & \multirow{3}{*}{$0.002 *$} \\
\hline$<$ Third centile & $4(100.0 \%)$ & $5(38.5 \%)$ & $4(18.2 \%)$ & $8(18.6 \%)$ & & \\
\hline$<$ Tenth centile & $0(0.0 \%)$ & $8(61.5 \%)$ & $18(81.8 \%)$ & $35(81.4 \%)$ & & \\
\hline
\end{tabular}

*-Significant

Table 8: Comparison chart between normal and abnormal Doppler Groups.

\begin{tabular}{|c|c|c|c|}
\hline Variable & $\begin{array}{l}\text { Doppler normal } \\
(n=54)\end{array}$ & $\begin{array}{l}\text { Doppler abnormal } \\
(\mathrm{n}=\mathbf{2 8})\end{array}$ & Significance ( $p$ value) \\
\hline Maternal age in years (mean) & 27.05 & 29.25 & \multirow[t]{2}{*}{-} \\
\hline Mean S/D ratio (umbilical artery) & 2.8 & 4.12 & \\
\hline Gestational age at diagnosis(mean) in weeks & 35.19 & 34.29 & $0.032 *$ \\
\hline Gestational age at delivery(mean) in weeks & 36.29 & 35.76 & 0.297 \\
\hline Diagnosis -delivery delay of 48 hours & 07 & 20 & $0.001 *$ \\
\hline Mean birth weight of neonate (grams) & 2201.80 & 1929.46 & $0.001 *$ \\
\hline NICU stay average (days) & 5.00 & 8.04 & $0.003 *$ \\
\hline Need for positive pressure ventilation & 01 & 16 & \\
\hline Severe neonatal morbidity $>10$ days NICU & 08 & 09 & - \\
\hline
\end{tabular}

\section{DISCUSSION}

Doppler patterns follow a longitudinal trend with early changes in the umbilical artery followed by middle cerebral artery and other peripheral arteries There is a strong association of abnormal umbilical artery velocity waveforms with foetal growth restriction. Umbilical artery velocimetry is really useful in those with the clinical suspicion of foetal growth restriction or with coexisting HDP with or without gestational diabetes, severe anaemia, and with history of bad obstetric history. Particularly at early gestational ages, and at whatever stage, coexistence of severe pre-eclampsia may distort the natural history and strict fetal monitoring is warranted since fetal deterioration may occur unexpectedly at any time. ${ }^{10}$ Among 82 growth restricted foetuses, 54 of them had normal Doppler patterns (65.85\%) and 28 had abnormal Doppler patterns (34.15\%). 13(46.5\%) had umbilical S/D elevation, $2(7.14 \%)$ had absent end diastolic flow, $1(3.57 \%)$ with reverse end diastolic flow and $12(42.8 \%)$ with brain sparing effect. Mahajan11 et al observed that the maximally affected foetal vessel was the umbilical artery showing abnormal velocimetry in $81 \%$. Reduced end diastolic flow velocity in the umbilical artery was seen in $65 \%$ women. AREDV was seen in $16 \%$ women. Brain sparing effect was seen in $58 \%$ FGR fetuses and AREDV in $10 \%$ in a prospective study by Arora et al, Baschaet al, and Martinez et al, noted that Cerebroplacental ratio of FGR fetuses was significantly lower than that of normal foetuses and CP ratio is found to be best of all. ${ }^{12-14}$ Radhika et al, noted $68 \%$ brain sparing effect in foetuses with growth restriction. ${ }^{15}$

In present study $39.28 \%$ had early FGR with Doppler abnormality (<34weeks) and it was only $14.8 \%$ with normal Doppler velocimetry. $46 \%$ patients were less than 34 weeks of gestation depicting an early onset of FGR and the incidence of abnormal umbilical artery Doppler decreased from $86 \%$ in $26-30$ weeks of gestation to $71 \%$ in $>37$ weeks of gestation in Mahajan et al. ${ }^{11}$ Turan et al opined that the rate of progression for Doppler abnormalities was significantly related to gestational age. ${ }^{10}$ When the abnormality presented early in gestation, it progressed more rapidly; when an abnormality emerged later, progression was slower. This was true for the Umbilical and middle cerebral flow defects. FGR babies with abnormal umbilical artery velocimetry had shorter diagnosis to delivery interval than those with normal Doppler and decision for delivery was taken at a lower gestational age after counselling regarding prematurity risks ( $p$ value-0.001). Only 7mothers in normal Doppler FGR had been terminated in 48 hours while in the same 
time frame, 20 abnormal pattern Doppler mothers underwent emergency caesarean. Three AREDV also in just three to four hours of sonological diagnosis. Diagnosis-Delivery Delay as 9.6days in UA abnormality and within 24hours in AREDV according to Rashmi et al. ${ }^{16}$ It was I day and 14hours respectively in Singh et al. ${ }^{17}$ Visentin and Arora et al, observed all live births in their study similar to the present study while Mazarico et al, observed $85 \%$ live births and $15 \%$ stillbirths. ${ }^{12,18,19}$ The variation in the sample size and the risk factors included can be attributed to the difference in the studies. Mahajan et al, in his study had 97\% livebirths and 3\% stillbirths. ${ }^{11} 85.71 \%$ of babies were low birth weight, 7.14 were VLBW in present study.56\% of babies were low birth weight, $35 \%$ were VLBW and $9 \%$ were ELBW babies in Mahajan et al. ${ }^{11}$ The mean birth weight in the present study was higher $(2201.80 \mathrm{gm})$ in Doppler normal FGR and it was $1929.46 \mathrm{gms}$ in abnormal umbilical Doppler group and $1363.33 \mathrm{gm}$ in AREDV (pvalue-0.001).Similar results were noted in Rashmi et al, where there is significant decrease in S/D and RI of umbilical artery as birth weight increases and the birth weight being higher in the normal Doppler group (2867 gm) and lowest in the absent/ reversed end diastolic flow group (1500gm) also in Fleischer et al, who demonstrated that those foetuses with lower birth weight $\left(<25^{\text {th }}\right.$ percentile) had higher placental vascular resistance than those with higher birth weight ( $>25$ th percentile). ${ }^{17,20}$ According to Malhotra et al, birth weight in abnormal Doppler group was $742 \pm 126 \mathrm{gm}$ and in normal Doppler group was $1680 \pm 259 \mathrm{gm}^{21}$

Similarly, present results showed that there was a significantly increase in duration of admission for NICU care in preterm FGR infants with umbilical artery absent/reversed end diastolic flow. Perinatal morbidity in terms of NICU days (mean) was highly significant implying that growth restricted foetuses with Doppler pattern abnormality stayed mean of 3days more than the Doppler normal group. (p-value:0.003). In consonance with present study Vergani et al, found that in FGR cases delivered at or beyond 34 weeks gestation with abnormal umbilical artery velocimetry, it independently predicts the likelihood of admission to the NICU for reasons other than low birth weight alone. ${ }^{22}$ Prolonged intensive neonatal stay in abnormal velocimetry was also highlighted in Rashmi et al. ${ }^{17}$ The need for positive pressure ventilation for resuscitation was more in foetus with absent / reversed diastolic flow studies. The foetuses with normal diastolic flow and with low diastolic flow had comparable requirement for positive pressure ventilation as in Arora et al. ${ }^{12}$

Authors noted that $68 \%(n=15)<37$ weeks with Doppler abnormality needed ventilator/CPAP for neonatal resuscitation while $38.46 \%$ with normal diastolic flow needed CPAP. Arora et al, opined that overall $40 \%$ $(n=36)$ of babies with normal umbilical artery Doppler studies were admitted to neonatal intensive care unit NICU in contrast to $70 \%(\mathrm{n}=21)$ with low-end diastolic velocity on umbilical artery Doppler. ${ }^{12}$ However all the foetuses with absent/reversed diastolic umbilical artery flow were admitted to the neonatal intensive care unit similar to present study.

Authors noted that the mean S/D ratio of umbilical artery in normal Doppler group $(n=54)$ was 2.8 and for the higher S/D ratio group $4.12(n=28)$ Two foetuses had AEDV and 1 had REDV. Arora et al, had the mean for the normal S/D ratio group $(n=90)$ was 2.6 and for the higher S/D ratio group $(n=30) 3.7 .{ }^{12}$ An additional 12 foetuses had absent end diastolic velocity and two fetuses had reversal of diastolic flow. Foetuses with abnormal MCA PI had a six-fold risk of emergency caesarean section for NRFHR which is particularly relevant because labour induction at term is the current standard of care of late-onset FGR as in present study ( $p$ value-0.001. This was also the finding in Arora et al, Akram et al. ${ }^{12,23}$ Our mothers had high incidence of pregnancy induced hypertension, diabetes mellitus and severe anaemia and hypothyroidism developing during the pregnancy and mean maternal age was slightly higher in abnormal Doppler than the normal Doppler group. According to Arora et al, $36.7 \%(n=11)$ foetuses with low-end diastolic velocity and $71.4 \%(\mathrm{n}=10)$ with absent/reversed diastolic flow were associated with maternal gestational hypertension and it was $21.4 \% \quad(n=6)$ in Doppler abnormal (UA and MCA)and all three cases of AREDF had severe HDP respectively. ${ }^{12}$ Early FGR presents in association with early PE in up to $50 \%{ }^{8}$ However, FGR mothers with normal umbilical artery Doppler studies also had a high incidence of $28.9 \% \quad(n=26)$ pregnancy induced hypertension and $20.03 \%(n=11)$ in present study. PIH constituted $35 \%$ of total cases in Mahajan et al. ${ }^{11}$ Pathology of AREDF were worsened with imminent eclampsia and HELLP but perinatal mortality in all three cases was averted with active foetal surveillance and timely caesarean. Mothers of FGR babies with abnormal Doppler studies were more likely to have history of obstetric complications in the previous pregnancy as observed by McCown et al. ${ }^{24}$

\section{CONCLUSION}

Colour Doppler study of fetal vessels is a simple, quick, non-invasive procedure and multiple vessel study has high accuracy for ante-partum foetal surveillance. If UA is abnormal, MCA /UA (CPR ratio) should be performed to know extent of brain sparing. FGR with normal umbilical flow velocimetry are at a lower risk than those with abnormal velocimetry in terms of prolonged decision-delivery interval, and shorter neonatal intensive care admission. The average birth weight of the neonates with abnormal umbilical artery Doppler was lower of compared to that of neonates with normal umbilical artery velocimetry. The application of nonstress test, biophysical scoring, multi-vessel Doppler surveillance and watch out for accelerated hypertension should guide the evaluation of such women for timing the delivery and averting perinatal mortality and morbidity. 


\section{ACKNOWLEDGMENTS}

Authors would like to thank the Department of Obstetrics and Gynecology and Department of Radiodiagnosis Travancore Medical College for their cooperation and support and all the patients without whom this study might not have been materialized.

\section{Funding: No funding sources}

Conflict of interest: None declared

Ethical approval: The study was approved by the Institutional Ethics Committee

\section{REFERENCES}

1. Mandruzzato G, Antsaklis A, Botet F, Chervenak FA, Figueras F, Grunebaum A, et al. Stanojevic M: Intrauterine restriction (IUGR). J Perinat Med. 2008;36(4):277-81.

2. Baschat AA. Fetal responses to placental insufficiency: an update. BJOG: Int $\mathbf{J}$ Obstet Gynaecol. 2004;111(10):1031-41.

3. Blössner M, Villar J. Levels and patterns of intrauterine growth retardation in developing countries. Europ $\mathrm{J}$ Clinic Nutr. 1998;52:S5-15.

4. Hecher $\mathrm{K}$, Campbell S, Doyle $\mathrm{P}$, Harrington $\mathrm{K}$, Nicolaides K. Assessment of fetal compromise by Doppler ultrasound investigation of the fetal circulation. Arterial, intracardiac, and venous blood flow velocity studies. Circulat. 1995;91:129-8.

5. Baschat AA, Cosmi E, Bilardo CM, Wolf H, Berg C, Rigano S, et al. Predictors of neonatal outcome in earlyonset placental dysfunction. Obstet Gynecol. 2007;109:253-61.

6. Berkowitz GS, Chitkara U, Rosenberg J, Cogswell C, Walker B, Lahman EA, et al. Sonographic estimation of fetal weight and Doppler analysis of umbilical artery velocimetry in the prediction of intrauterine growth retardation: a prospective study. Am J Obstet Gynecol. 1988;158(5):1149-53.

7. DeVore GR. The importance of the cerebroplacental ratio in the evaluation of fetal well-being in SGA and AGA fetuses. Am J Obstet Gynecol. 2015;213:5-15.

8. Figueras F, Gratacos E. Update on the diagnosis and classification of fetal growth restriction and proposal of a stage-based management protocol. Fetal Diagn Ther. 2014;36(2):86-98.

9. Imdad A, Yakoob MY, Siddiqui S, Bhutta ZA. Screening and triage of intrauterine growth restriction (IUGR) in general population and high risk pregnancies: a systematic review with a focus on reduction of IUGR related stillbirths. BMC Public Health. 2011;11(3):S1.

10. Turan OM, Turan S, Gungor S, Berg C, Moyano D, Gembruch U, et al. Progression of Doppler abnormalities in intrauterine growth restriction: Ultrasound Obstet Gynecol. 2008;32:160-7.

11. Mahajan A, Seth S. Role of colour Doppler in the evaluation of fetal growth restriction: a prospective study. Int J Scientific Res. 2017;11(6):32-4.
12. Devendra A, Desai SK, Sheth PN, Prema K. Significance of umbilical artery velocimetry in perinatal outcome of growth restricted foetuses. J Obstet Gynecol India. 2005;55:138-43.

13. Baschat AA, Gembruch U: The cerebroplacental Doppler ratio revisited. Ultrasound Obstet Gynecol. 2003;21:124-7.

14. Cruz-Martinez R, Figueras F, Hernandez-Andrade E, Puerto B, Gratacós E. Longitudinal brain perfusion changes in near-term small-for-gestational-age fetuses as measured by spectral Doppler indices or by fractional moving blood volume. Am J Obstet Gynecol. 2010;203(1):42-e1.

15. Radhika P, Shetty C, Rai L. Multivessel foetal Doppler and perinatal outcome in IUGR and severe preeclampsia. J Obstet Gynecol. 2006;11(2):106-9.

16. Singh S, Kumar P, Nema D. Umbilical artery Doppler study in perinatal outcome of fetuses with FGR: a prospect cohort study. IOSR-JDMS. 2016;15(11):32-6.

17. Rashmi L, Bhattacharjee A. Umbilical artery Doppler indices in relation to fetal outcome in high risk pregnancy. Int $\mathbf{J}$ Reprod Contracept Obstet Gynecol. 2018;7:628-3.

18. Visentin S, Cavallin F, Zanardo V, Cosmi E. Neonatal outcome in intrauterine growth restricted and small for gestational age fetuses. Ultrasound Obstet Gynecol. 2010;36(10):52-67.

19. Mazarico E, Roig Gomez M, Sabria J, Ancel Martin A, Vela A, et al. Perinatal outcomes in gestations with intrauterine growth restriction and small for gestational age foetuses. Ultrasound Obstet Gynecol. 2010;36(1):52-67.

20. Fleischer A, Schulman H, Farmakides G, Bracero L, Blattner P, Randolph G. Umbilical artery velocity waveforms and intrauterine growth retardation. Am J Obstet Gynecol. 1985;151(4):502-5.

21. Malhotra N, Puri R, Malhotra J, Malhotra N, Rao JP. Maternal-fetal work-up and management in intrauterine growth restriction (IUGR). Donald Sch J Ultrasound Obstet Gynecol. 2010;4(4):427-32.

22. Vergani P, Andreotti C, Roncaglia N, Zani G, Pozzi E, Pezzullo JC, et al. Doppler predictors of adverse neonatal outcome in the growth restricted fetus at 34 weeks' gestation or beyond. Am J Obstet Gynecol. 2003;189(4):1007-11.

23. Humaira Akram, Tabassum Firdou A Comparison of Fetal Outcome in Pregnant Women with Fetal Growth Restriction in Normal and Abnormal Umbilical Artery Doppler. P J M H S. 2013;7(4): 1063-5.

24. Mc Cowen LM, Harding JE, Roberts AB. A pilot randominized controlled trial of two regimes of foetal survelliance for small for gestational age foetuses with abdominal umbilical artery Doppler. Ultrasound Obstet Gynecol. 2002;19:225-8.

Cite this article as: Shenoy HT, Shenoy S, James SX. Doppler patterns in growth restricted foetuses determinants and outcome in a tertiary hospital in South Kerala, India. Int J Reprod Contracept Obstet Gynecol 2019;8:453-61. 